University of South Florida

DIGITAL COMMONS

Digital Commons @ University of

@ UNIVERSITY OF SOUTH FLORIDA

South Florida

$10-15-2014$

\title{
Scholarly Excellence, Leadership Experiences, and Collaborative Training: Qualitative Results from a New Curricular Initiative
}

Lori A. Roscoe

University of South Florida, Iroscoe@usf.edu

Allesa English

University of South Florida

Alicia D. H. Monroe

Baylor College of Medicine

Follow this and additional works at: https://digitalcommons.usf.edu/spe_facpub

Part of the Communication Commons

\section{Scholar Commons Citation}

Roscoe, Lori A.; English, Allesa; and Monroe, Alicia D. H., "Scholarly Excellence, Leadership Experiences, and Collaborative Training: Qualitative Results from a New Curricular Initiative" (2014). Communication Faculty Publications. 880.

https://digitalcommons.usf.edu/spe_facpub/880

This Article is brought to you for free and open access by the Department of Communication at Digital Commons @ University of South Florida. It has been accepted for inclusion in Communication Faculty Publications by an authorized administrator of Digital Commons @ University of South Florida. For more information, please contact digitalcommons@usf.edu. 


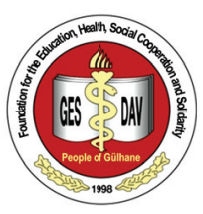

GESDAV
Scholarly excellence, leadership experiences, and collaborative training: Qualitative results from a new curricular initiative

\author{
Lori A. Roscoe', Allesa English², Alicia D. H. Monroe ${ }^{3}$
}

\begin{abstract}
Objective: Developing effective leaders in medicine is an educational issue and requires a medical school culture that recognizes, develops, and rewards leadership. This study provides a qualitative evaluation of the initial outcomes from the Scholarly Excellence, Leadership Experiences, and Collaborative Training (SELECT) program, developed by the University of South Florida Health Morsani College of Medicine as a training model for physician leadership and patient-centered care based on emotional intelligence. Methods: Semi-structured interviews were conducted with $1^{\text {st }}$ year students and faculty involved in program development and implementation to elicit descriptions of their experiences. Field notes were analyzed using a constant comparative method to identify key words and themes. Results: Themes from students included: Acknowledging imperfection while pursuing excellence; embracing patient-centered care, and identifying as physician-leaders. Themes from faculty included: Believing in the teaching mission of the SELECT program, and viewing participation as an opportunity for personal and professional development. Participants described the transformational and empowering aspects of participating in a program that used emotional intelligence to train future physicians to practice medicine and lead change in team-based, patient-centered healthcare contexts. Conclusions: The initial success of the SELECT program demonstrates the value of early investments in self-awareness and coaching relationships for developing leadership skills in medical students.
\end{abstract}

KEY WORDS: Emotional intelligence, leadership development, undergraduate medical education

\section{INTRODUCTION}

The development of strong and effective leaders in medicine, as in every other discipline, is very much an educational issue. Providing a set of leadership and management skills to today's senior doctors is of no value whatsoever unless it is underpinned by a commitment to developing these skills in our doctors currently in training and in medical school [1].

Leadership skills in medicine are scarce resources essential for the field to adapt to current and future challenges. The literature reports results of leadership development programs for faculty but programs for undergraduate medical students appear less often $[2,3]$. The medical leaders of the future must be equipped to understand and thrive in the complex environment of health care delivery, learn to work effectively in teams, and be prepared to meet a wide range of social needs [4]. Medical educators must create innovative curricula, and also create a culture that identifies, develops and rewards a new set of competencies. Trends including growing consumerism among patients, demands for patient-centered care, and the expansion of clinical competencies such as mindfulness, reflective learning, communication and interpersonal skills make it essential that future physician-leaders cultivate self-awareness and relationship skills [5-9].

Leadership is a set of learnable competencies, and the self-confidence to lead comes from learning about oneself, including skills, biases, and shortcomings, and developing self-awareness about how these characteristics manifest in relationships with others, who of course have their own unique characteristics [10]. The corporate world embraced emotional intelligence (appraising, expressing, regulating and utilizing emotional content in problem-solving) as a means of leadership development, and while emotional intelligence has not been widely applied to medical education, it is equally relevant [11-13]. 
The University of South Florida (USF) Health Morsani College of Medicine (MCOM) developed and implemented a new medical education program, Scholarly Excellence, Leadership Experiences, and Collaborative Training, (SELECT), that uses the concepts of emotional intelligence to promote leadership development. The SELECT program was developed in partnership with Lehigh Valley Health Network (LVHN) in Allentown, Pennsylvania, and admitted the first cohort in 2011. Students meet the same academic standards as all students admitted to USF's medical education programs and are admitted based on the results of a proprietary behavioral event interview to assess leadership potential and emotional intelligence.

SELECT is a 4-year MD program; students spend their first 2 years at MCOM Tampa campus with the larger medical school class and devote approximately 4 additional hours each week to seminars, coaching sessions, peer-mentoring, research, and tailored clinical experiences. Students spend the second 2 years at LVHN, under the supervision of physician coaches who are specially selected and trained. The overall goal of the SELECT program is to identify students with leadership potential and enroll them in an enhanced MD curriculum that emphasizes emotional intelligence and self-awareness, promotes patientcentered care, and provides intensive coaching so students are prepared for future leadership positions.

The present study reports results from interviews with SELECT program students after their $1^{\text {st }}$ year in medical school and with faculty members associated with program development and implementation. One-on-one interviews with someone outside the medical school provided an opportunity to share candid impressions and provide feedback. A study of local narratives such as this offers a deeper understanding of participants' experiences and demonstrates how people do things together in the process of making meanings and exploring values [14]. Recent social-psychological research on educational interventions has revealed the lasting benefit of hearing certain transformational messages at key points in one's education, such as the transition from an undergraduate college degree program to medical school [15]. Brief exercises that target students' thoughts, feelings and beliefs can lead to large gains in student achievement even months and years later. These interventions do not focus on academic content as such but instead target students' psychology, such as their beliefs that they have the potential to improve their intelligence, attain future leadership positions, and make significant changes in their chosen field. These benefits are enhanced if students are encouraged to rephrase these messages and beliefs in their own words. The present study used a similar self-reflective method to allow students to rephrase the transformational messages of the SELECT curriculum into their own words. The goals were to both document students' (and faculty members') perceptions about the objectives and outcomes of the new curriculum, as well as increase the likelihood that these messages would have lasting value as students proceed through the program and on into their clinical and residency training.

\section{METHODS}

The study was approved by the USF Institutional Review Board, and all participants provided informed consent. All 18 students admitted to the SELECT program in the initial cohort received an email inviting them to schedule an individual interview. 15 of the 18 students participated in semi-structured interviews that explored perceptions of the program's purpose and goals, experiences with and perceptions of patient-centered care, and the relationship between emotional intelligence and being a good doctor. Interviews took place in a private office on campus and lasted an average of $45 \mathrm{~min}$. 20 individuals involved with the SELECT program from MCOM and LVHN also received emails inviting them to participate. Nine participated in interviews lasting approximately $30 \mathrm{~min}$, either in person, by telephone, or using a web-cam interface. Extensive field notes were taken during the interviews, which were analyzed using a constant comparative method to identify key words, phrases, and themes $[16,17]$.

\section{RESULTS}

\section{Themes from Medical Student Responses}

Students in the SELECT program expressed their pride in the program and saw value in the enhanced curriculum. The following themes were revealed:

- Acknowledging imperfection while pursuing excellence;

- Embracing models of empathic, patient-centered care; and

- Identifying as physician-leaders.

\section{Imperfection in the pursuit of excellence}

Students admitted to medical school are sometimes unwilling to change the behaviors and attitudes that enabled their past successes. Encouraging medical students to be vulnerable, explore alternative means of achieving goals, and rely on others requires consistent reassurance, freedom to take risks, and the active involvement of role models who demonstrate these values. Students mentioned "needing to learn continuously and improve, rather than needing to know everything." One said, "I'm learning to be comfortable knowing 'this is in the realm of the right answer,' instead of hanging on to the certainty that this is the right answer and the 'only' answer." This is in contrast to faculty members' recollections of times they felt unequal to the task of "knowing it all" when they were medical students. Students recalled examples of clinical mentors having to look something up (like a particular medication dosage) and who were unapologetic in front of patients, peers, or medical students. This is critically important: It is one thing to tell medical students life-long learning is important while at the same time participating in behaviors that reinforce the message in the "hidden curriculum" that physicians must be infallible, and another to demonstrate how one might act when information has to be double-checked or solicited from a provider in another discipline.

Students stressed the SELECT program has personal and professional development as a primary goal; one student said, 
"At first some of us doubted it, but we are really starting to believe that personal and professional development is the goal of this curriculum." Students talked about setting goals, developing action plans, and documenting tangible successes. A wide range of goals was reported, including developing better listening and public speaking skills, as well as more personal goals involving stress management and wellness.

Students discussed identifying strengths and improving weaknesses, learning to do things differently, and giving and accepting feedback:

Before I became part of SELECT, I didn't realize I was often working against my own strengths and goals, or that there were ways I might consider doing things differently.

The SELECT program was credited with helping students achieve goals:

I have always been a person who sets goals, but I would often stop before I achieved them. SELECT doesn't let you get away with that. I have learned that nothing I want is beyond my reach.

Students spoke about the advantages of multi-disciplinary approaches to patient care, and the value in relying on the contributions of other disciplines:

I really am learning to notice the value of a team approach and how patients respond to different personalities and disciplines. Sometimes the medical piece isn't what makes the most difference in what the patient learns or does.

Medical students' experiences with multi-disciplinary care are important due to the growing ranks of allied health providers and their role in improving access to care [18]. Addressing the needs of patients with chronic illnesses is an increasingly urgent task for physicians and often requires doctors to function effectively as members of multi-disciplinary teams [19].

\section{Patient-centered care}

Students described patient-centered care as "a mind set that puts the patient in the center of health care," and as "a shift in ideology from doctors and the health care system, to patients and the relationship between doctors and patients." Being a good listener and communication skills in general were mentioned more often than scientific knowledge or technical skills. Students talked about the importance of "being a good listener," and "letting patients tell their stories," along with empathy, normalizing patients' concerns, and finding out what is important to patients. Developing relationships, self-awareness, honesty, work ethic, trustworthiness, and respect for oneself and others were also reported. Students are making connections between emotional intelligence, particularly self-awareness and awareness of others, and communication skills:

It seems intuitively obvious that those who are emotionally intelligent will be better doctors. Awareness of self and others, teamwork, communication, self-control--these are critically important.
Only one student said "compliance" when discussing how to best care for patients with serious chronic illnesses, and quickly switched to "adherence," and then to "how I might be able to influence a patient to do the right things for their health." Almost every response included the importance of empowering patients, and of doctors learning to play a supporting role:

Patients need to be empowered with the responsibility to take care of themselves, with a doctor in a supporting role, not the other way around.

Students stressed the need to learn what a patient values; one said "things other than health might be bothering the patient or interfering in their health." Students were also learning to be realistic about behavior change:

No one does everything they are supposed to do $100 \%$ of the time, so we can't expect this of our patients. Maybe $80 \%$ is a better goal. You have to meet patients where they are and help them have realistic expectations.

Self-identification as physician-leaders

Students in the SELECT program described themselves as physician-leaders as opposed to physician-scientists, with a desire to embrace and lead changes in health care:

Being in SELECT makes me hyper-aware, in a good way, of potential communication problems and patient safety issues. The curriculum provides a set of tools we can use to intervene and create positive changes in health care, and a vocabulary to talk about and analyze issues we might have noticed but not had a way to discuss.

Students are required to master topics, like health care reform, and complete assessments on leadership and learning styles, that are quite distant from subjects that will comprise the United States Medical Licensing Examination Step 1 exam. Rather than frustration, students expressed appreciation for this early and pragmatic introduction to the realities of health care.

\section{Themes from Faculty Responses}

Faculty members associated with the SELECT program were enthusiastic about the program, motivated to continue their involvement, eager to develop inter-institutional partnerships, and pleased to be able to focus on and implement aspects of leadership, emotional intelligence, and patient-centered care into their own clinical practices. The following themes were revealed: - Belief in the teaching mission of the SELECT program and its emphasis on emotional intelligence and leadership; and

- Participating in the SELECT program as an opportunity for personal and professional faculty development.

\section{SELECT's teaching mission}

The integral relationship between the practice of medicine and teaching with both students and patients was highlighted. Faculty involved with the SELECT program enjoyed close 
relationships with students and noted the difference in the classroom environment:

The classroom environment is very different when it's just SELECT students and faculty. The larger classroom environment can be hostile at times, like when someone asks a question, and derisive laughter follows. That doesn't happen with just SELECT students and faculty, and I wish it didn't happen in the larger class.

Faculty participants believed the SELECT curriculum was appropriately focused on the skills future physicians in leadership roles would need to be successful:

The SELECT curriculum emphasizes the things that will help doctors, in the changing world of medicine, find meaning, purpose and satisfaction in their work.

Faculty members stressed the changing nature of health care, and the need to match the curriculum to the challenges students will face:

SELECT is a program to produce tomorrow's health care leaders today. I know it sounds like a sound bite, but that's really what we are all about.

\section{SELECT as faculty development}

Faculty talked about changing their own approaches to leadership and patient care:

I am learning that leaders do things with and for others, rather than doing things to or at them. I am learning to say, 'I am here to help you get where you need to go,' rather than "what can you do for me?"

Another said:

I am more willing to hear where the students are coming from. I'm more willing to entertain different perspectives than I was when I thought I had to have all the answers for students.

Faculty members were motivated by relationships with likeminded peers across institutional settings, and were willing to contribute the extra time and effort required. Everyone involved in the program initially intended to continue or expand their roles in the program. Several faculty participants noted their involvement with the SELECT program was " $m y$ favorite part of the week," and "it reminds me why I do the work that I do."

\section{DISCUSSION}

The SELECT program is creating an opportunity for students to become self-aware, collaborative physician-leaders capable of delivering patient-centered care in a changing healthcare landscape, while simultaneously creating opportunities for faculty members to develop relationships that enrich their own medical practices. Students are beginning to make connections between emotional intelligence and good doctoring, and are establishing goals for personal and professional success. Faculty members support program goals, intend to continue their involvement, and see their participation as a valuable source of continuing professional development.

Students' responses to questions about characteristics of a good doctor, and those of their much more senior, albeit like-minded, faculty coaches overlapped. All participants emphasized the need to develop good communication skills in order to demonstrate empathy for their patients. The SELECT program is an opportunity to examine what happens when students who were chosen for leadership, empathy and emotional intelligence enter medical school, where in the past such attributes were not as highly valued. Deterioration in empathy among medical students has been measured as students encounter the hidden curriculum, including mistreatment by superiors, inadequate role models, and emphasis on technology and objectivity [20-23]. Students in the SELECT program recognized empathy for their patients and their peers as a characteristic of doctors they admire, and as a central component of patient-centered care. Students are beginning to make connections between patient-centered care, emotional intelligence, and leadership, but did not seem to have a perspective on how unusual and non-normative their assumptions were.

The SELECT curriculum makes explicit the notion that high quality care is patient-centered, and includes best practices in medical education such as active role modeling, discussions around role-modeled behaviors, debriefing of seminal events, and critical framing of patient care activities by learners [24]. Favorable attitudes toward patient-centered care, as well as communicative and affective skills, are associated with more favorable patient outcomes $[25,26]$. Skills can be taught in didactic and clinical encounters, but attitudes toward patientcentered care can be negatively affected by the values and viewpoints endorsed in the hidden curriculum [27].

Students in the SELECT program appear to have embraced the role of change agent rather than expert, and have begun to develop definitions of health, especially for patients with chronic illnesses, that emphasize resilience and adaptability [28]. These students are coming to believe that patients with chronic illnesses need to be empowered to see that making changes in their health is possible and can be a personal goal, rather than compelling them to comply to with physician-centered care plans.

As with any new endeavor, challenges remain. Students raised concerns about explaining the program to residency directors, and expressed some trepidation about being in two very different institutions over a 4-year period. Short-and long-term metrics that track student success are essential. Board scores and residency placement can be tracked as evidence of the students' educational achievements. Eliciting behavioral examples of the students' progress from faculty could provide additional evidence of their development. One faculty member recounted an incident in which a student politely, but directly, challenged a senior physician's beliefs about how to best get a patient to change smoking behavior; the faculty member was proud and somewhat amazed that a $1^{\text {st }}$ year student would have the 
confidence and skill to initiate this discussion. Another talked about interactions with students in which they "didn't sound like $1^{\text {st }}$ year medical students." During residency, the number of SELECT program students who become Chief Resident, Active Members of Patient Safety Committees, or who take on other leadership roles can be tracked; longer term, students' career trajectories and achievements can be monitored.

The narrative methods employed here to elicit, record and analyze medical students' and faculty members' stories of their experiences with the program provided useful preliminary data about the program's effectiveness in developing leadership skills and a focus on patient-centered care. Such methods can be usefully employed in other contexts where it is important to have early results of success, but where the real success of the intervention or program will only be known in the rather distant future. There is substantial research evidence, however, that allowing students at transitional points in their education to reflect and put into their own words observations about their psychological state and reactions to new information can have lasting impact on student achievement even months and years later [15].

These preliminary results demonstrate the ways in which the SELECT curriculum can serve as a model program to prepare medical students to become leaders in the changing world of medicine and health care. Students and faculty associated with the SELECT program reported the transformational and empowering aspects of putting emotional intelligence to work in the service of patient-centered, multi-disciplinary team-based care. Early investment in self-awareness and coaching relationships may provide crucial support as these students confront increasing levels of challenge and responsibility. Ongoing program evaluation and narrative studies such as this can provide guidance for modifying the program, and evidence of the program's success. The lessons of the SELECT curriculum are important, difficult, and sophisticated

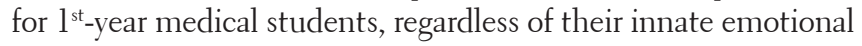
intelligence, drive for excellence, or leadership potential. These results demonstrate the initial success of the SELECT program to identify and inspire a group of students and faculty members who believe strongly in its objectives, and are eager and confident that future challenges can be met as the program continues to grow.

\section{ACKNOWLEDGMENTS}

The authors acknowledge the support of Nicole Johnson, Executive Director of Bringing Science Home, an initiative to create new models for chronic disease education and to empower patients with chronic illnesses to live optimistically, for her support of this project.

\section{REFERENCES}

1. Making and preparing leaders Med Educ 2000;34:211-5.

2. Sanfey H, Harris I, Pollart S, Schwartz A. Evaluation of the University of Virginia leadership in academic medicine program. Teach Learn Med 2011;23:347-58.

3. Rosenbaum ME, Lenoch S, Ferguson KJ. Outcomes of a teaching scholars program to promote leadership in faculty development. Teach Learn Med 2005;17:247-52.

4. Hodges BD. A tea-steeping or i-Doc model for medical education?
Acad Med 2010;85:S34-44.

5. Carrothers RM, Gregory SW Jr, Gallagher TJ. Measuring emotional intelligence of medical school applicants. Acad Med 2000;75:456-63.

6. Epstein R. Mindful practice in action: Technical competence, evidence based medicine, and relationship centered care. Fam Syst Health 2003:21:1-9

7. Plsek PE, Greenhalgh T. The challenge of complexity in health care. Br Med J 2001;323:625-8.

8. Feldman MD. Becoming an emotionally intelligent physician. West J Med 2001;175:98.

9. Saba GW, Villela TJ, Chen E, Hammer H, Bodenheimer T. The myth of the lone physician: Toward a collaborative alternative. Ann Fam Med 2012;10:169-73.

10. Kouzes JM, Posner BZ. The Leadership Challenge. San Francisco: Jossey Bass Inc.; 1987.

11. Eubank D, Geffken D, Orzano J, Ricci R. Teaching adaptive leadership to family medicine residents: What? Why? How? Fam Syst Health 2012;30:241-52

12. Gupta A, Koolwal GD, Gehlot S. Study of the perceived stress and emotional intelligence among $1^{\text {st }}$ year medical undergraduates in India. J Contemp Med Educ 2014;2:63-7.

13. Stratton TD, Saunders JA, Elam CL. Changes in medical students' emotional intelligence: An exploratory study. Teach Learn Med 2008;20:279-84.

14. Bochner AP. Perspectives on inquiry II: Theories and stories. In: Knapp M, Miller GR, editors. Handbook of Interpersonal Communication. $2^{\text {nd }}$ ed. Thousand Oaks, CA: Sage; 1994.

15. Yeager DS, Walton GM. Social-psychological interventions in education: They're not magic. Rev Educ Res 2011;81:267-301.

16. Glaser BG, Strauss AL. The Discovery of Grounded Theory: Strategies for Qualitative Research. Chicago: Aldine; 1967.

17. Scott CR. Anonymity in applied communication research: Tensions between IRBs, researchers, and human subjects. J Appl Commun Res 2005;33:242-57.

18. Peccoralo LA, Callahan K, Stark R, DeCherrie LV. Primary care training and the evolving healthcare system. Mt Sinai J Med 2012;79:451-63.

19. Turner J, Pugh J, Budiani D. "It's always continuing": First-year medical students' perspectives on chronic illness and the care of chronically ill patients. Acad Med 2005;80:183-8.

20. Hojat M, Vergare MJ, Maxwell K, Brainard G, Herrine SK, Isenberg GA, et al. The devil is in the third year: A longitudinal study of erosion of empathy in medical school. Acad Med 2009;84:1182-91.

21. Neumann M, Edelhäuser F, Tauschel D, Fischer MR, Wirtz M, Woopen $\mathrm{C}$, et al. Empathy decline and its reasons: A systematic review of studies with medical students and residents. Acad Med 2011;86:996-1009.

22. Newton BW, Barber L, Clardy J, Cleveland E, O'Sullivan P. Is there hardening of the heart during medical school? Acad Med 2008;83:244-9.

23. Rosenthal S, Howard B, Schlussel YR, Herrigel D, Smolarz BG, Gable B, et al. Humanism at heart: Preserving empathy in third-year medical students. Acad Med 2011;86:350-8.

24. Branch WT Jr, Kern D, Haidet P, Weissmann P, Gracey CF, Mitchell G, et al. The patient-physician relationship. Teaching the human dimensions of care in clinical settings. JAMA 2001;286:1067-74.

25. Haidet P, Dains J, Paterniti DA, et al. Medical student attitudes toward the physician-patient relationship. J Gen Intern Med 1999;14 Suppl 2:138

26. Haidet P, Kelly PA, Chou C, Communication, Cirriculum, and Culture Study Group. Characterizing the patient-centeredness of hidden curricula in medical schools: Development and validation of a new measure. Acad Med 2005;80:44-50.

27. Hafferty FW. Beyond curriculum reform: Confronting medicine's hidden curriculum. Acad Med 1998;73:403-7.

28. Zubialde JP. Leading change versus managing care: The role of change agent in family medicine. Fam Med 2001;33:133-6.

(c) GESDAV; licensee GESDAV. This is an open access article licensed unde the terms of the Creative Commons Attribution Non-Commercial License (http://creativecommons.org/licenses/by-nc/3.0/) which permits unrestricted, non-commercial use, distribution and reproduction in any medium, provided the work is properly cited

Source of Support: Nil, Conflict of Interest: None declared. 